\title{
Complex signatures of genomic variation of two non-model marine species in a homogeneous environment
}

\author{
Erica S. Nielsen ${ }^{1}$, Romina Henriques ${ }^{1}$, Robert J. Toonen², Ingrid S. S. Knapp², Baocheng Guo ${ }^{3}$
} and Sophie von der Heyden ${ }^{1 *}$ (D)

\begin{abstract}
Background: Genomic tools are increasingly being used on non-model organisms to provide insights into population structure and variability, including signals of selection. However, most studies are carried out in regions with distinct environmental gradients or across large geographical areas, in which local adaptation is expected to occur. Therefore, the focus of this study is to characterize genomic variation and selective signals over short geographic areas within a largely homogeneous region. To assess adaptive signals between microhabitats within the rocky shore, we compared genomic variation between the Cape urchin (Parechinus angulosus), which is a low to mid-shore species, and the Granular limpet (Scutellastra granularis), a high shore specialist.
\end{abstract}

Results: Using pooled restriction site associated DNA (RAD) sequencing, we described patterns of genomic variation and identified outlier loci in both species. We found relatively low numbers of outlier SNPs within each species, and identified outlier genes associated with different selective pressures than those previously identified in studies conducted over larger environmental gradients. The number of population-specific outlier loci differed between species, likely owing to differential selective pressures within the intertidal environment. Interestingly, the outlier loci were highly differentiated within the two northernmost populations for both species, suggesting that unique evolutionary forces are acting on marine invertebrates within this region.

Conclusions: Our study provides a background for comparative genomic studies focused on non-model species, as well as a baseline for the adaptive potential of marine invertebrates along the South African west coast. We also discuss the caveats associated with Pool-seq and potential biases of sequencing coverage on downstream genomic metrics. The findings provide evidence of species-specific selective pressures within a homogeneous environment, and suggest that selective forces acting on small scales are just as crucial to acknowledge as those acting on larger scales. As a whole, our findings imply that future population genomic studies should expand from focusing on model organisms and/or studying heterogeneous regions to better understand the evolutionary processes shaping current and future biodiversity patterns, particularly when used in a comparative phylogeographic context.

Keywords: Genomics, RAD-seq, Comparative phylogeography, SNP, Local adaptation, Population differentiation

\footnotetext{
* Correspondence: svdh@sun.ac.za

1 Evolutionary Genomics Group, Department of Botany and Zoology,

University of Stellenbosch, Private Bag X1, Matieland, 7602, South Africa

Full list of author information is available at the end of the article
}

(c) The Author(s). 2018 Open Access This article is distributed under the terms of the Creative Commons Attribution 4.0 International License (http://creativecommons.org/licenses/by/4.0/), which permits unrestricted use, distribution, and reproduction in any medium, provided you give appropriate credit to the original author(s) and the source, provide a link to the Creative Commons license, and indicate if changes were made. The Creative Commons Public Domain Dedication waiver (http://creativecommons.org/publicdomain/zero/1.0/) applies to the data made available in this article, unless otherwise stated. 


\section{Background}

Disentangling the contributions of evolutionary processes through space and time is central to interpreting genetic signals of population dynamics and understanding how the environment shapes a species' distribution $[1,2]$. The evolutionary trajectories of species are also important for conservation management, particularly under anthropogenically driven environmental change, which has heavily influenced the spatial distribution of many species over relatively short evolutionary timescales [3]. From a conservation perspective, intraspecific genomic variation is a principal component of evolutionary diversification, and is an important feature to help prioritize populations with higher adaptive potential [4-7].

An increasing number of studies are utilizing highthroughput sequencing methodologies to assess the intraspecific adaptive potential of species and evaluate how genetic variation is associated with environmental heterogeneity [8-10]. However, the majority of studies directed at identifying genes under selection do so with model organisms, and over large areas with strong environmental gradients, where local adaptation is to be expected (see for example [11-16]). Fewer studies characterize genetic differentiation over relatively small and/or environmentally homogeneous regions (although see $[17,18]$ for microhabitat examples), leaving genome-wide variation of species within these types of environments unexplored. Furthermore, studies utilizing genomic data to conduct comparative phylogeographic analyses remain underrepresented in the literature, although the power of including multiple taxonomic groups into evolutionary studies is well recognized for mitochondrial DNA (mtDNA), nuclear DNA and microsatellites [19-21]. Despite the marked increase in data available with genomic tools, comparative analyses are still required for understanding the underlying processes shaping genomic variation across landscapes, as well as producing representative conservation plans [22, 23]. Comparative approaches also provide opportunities to test whether different species respond to the same environmental drivers in similar ways, or whether signals of selection differ across species and their populations [24, 25], and the scales at which selection acts [17].

The South African west coast is a relatively short, linear and homogeneous coastline with little variation in sea surface temperature (SST) and primary productivity (Fig. 1; [26]). The west coast is a highly-threatened region of the South African coastline, with exposure to diamond, oil and gas mining as well as fishing pressures [27, 28]. It is situated within the southern Benguela Upwelling System, one of the most productive eastern boundary currents in the world [29], and is heavily influenced by the Benguela Current, which flows along the South African coastline from south to north (Fig. 1; [30, 31]). Despite this dominant northward flowing current, multiple studies show variable genetic structuring for species along the South African west coast [32-37], with evidence of local oceanography such as eddies appearing to shape genetic differentiation of coastal species in this region [37]. We chose six rocky shore sample sites within the study region, which are evenly spaced at $\sim$ every $100 \mathrm{~km}$ of the coastline (Fig. 1). These sample sites were chosen to capture the full range of coastal habitat types, habitat conditions, ecoregions and protection levels along the South African west coast [27, 28].

Despite geographic conditions often playing important roles in shaping the biodiversity patterns of species [38, 39] the effects of environmental and ecological features on intraspecific genomic variation and adaptation still remain unclear for many sessile marine species with planktonic larvae [40]. To investigate the phylogeographic patterns of these marine species with larval distribution stages, we selected two rocky shore study species, namely the Cape urchin (Parechinus angulosus, Leske 1778) and the Granular limpet (Scutellastra granularis, Linneaus 1758), collecting 40 individuals from each sample site. We chose these two taxa as they represent different ecological niches, with the Granular limpet being a high shore species with a relatively short pelagic larval duration (PLD; 10 days) and the Cape urchin being a mid to low shore species with a relatively long PLD ( 50 days $[41,42])$. Although they have similar range distributions, previous phylogeographic patterns measured with mtDNA Cytochrome Oxidase subunit 1 (COI) showed contrasting genetic structuring for the two species, with the limpet displaying low genetic differentiation, compared to the high levels of genetic differentiation of the urchin $[35,42])$. Because non-model species (i.e. those without annotated genomes) are underrepresented in genomic studies, and because of the lack of genome projects focused on South African marine species, we chose to study two non-model organisms and utilize de novo assemblies as reference sequences [43-45].

Here we use pooled ezRAD sequencing, a size-selectionbased reduced representation genomic sequencing approach [46], to build on previous comparative studies using mtDNA markers [32, 33, 35], which should provide more powerful results for genome-wide variation and selective signals on two non-model species. We also use genomewide SNP datasets to compare patterns of genomic variation and population structure between species. We expect to find high levels of genomic diversity, yet low levels of selection in both species, and to identify genes associated with different selective pressures than those previously identified in marine taxa occurring in regions with larger environmental gradients. Largely, this study aims to compare the distribution of genomic variation between two sessile marine species, so as to better understand the processes shaping the evolutionary history of species within a highly productive and threatened coastline. 


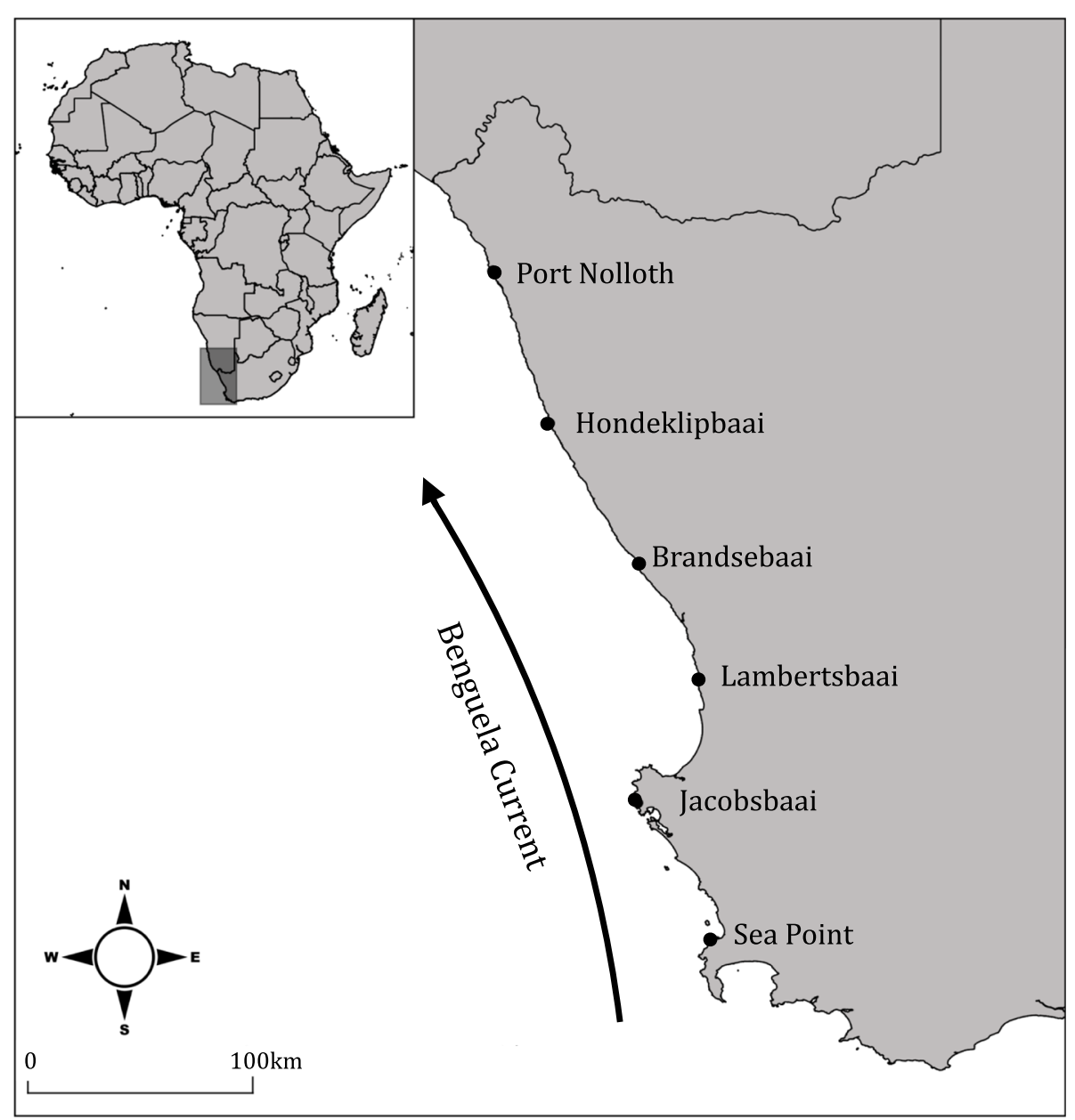

Fig. 1 The six sample locations in which 40 individuals of each species were collected for genomic analyses, along with the dominant current in the study region

\section{Results}

\section{Sequencing and assembly}

A total of 35.4 million paired reads were obtained from the Granular limpet libraries, with an average of 5.9 million paired reads per sample (from hereon referred to as population). The de novo assembly produced a total of 452,948 contig sequences, which were combined to create the reference sequences for all downstream analyses (Additional file 1: Table S1). The Granular limpet de novo assembly was roughly $180 \mathrm{Mb}$ in length, the longest contig was $12,107 \mathrm{bp}$, and the N50 and L50 were $717 \mathrm{bp}$ and $87,790 \mathrm{bp}$, respectively (Additional file 1: Table S1). A total of 25 million reads were mapped onto the reference sequences, and the number of mapped reads ranged from 3.4 to 4.7 million per population (Table 1). The average length of mapped reads for the limpet was $252 \mathrm{bp}$, and the average base quality of the mapped reads was 35.3 Phred.

The Cape urchin libraries yielded 27.3 million paired reads, with an average of 4.5 million paired reads per population, resulting in 453,847contig sequences from the de novo assembly (Additional file 1: Table S1). This assembly was $\sim 200 \mathrm{Mb}$ in length, the longest contig was 265,371 bp, and the N50 and L50 were 719 and 94,187, respectively (Additional file 1: Table S1). After mapping, 19 million reads were aligned to the urchin reference sequences, and total mapped reads ranged from 2.3 to 4.4 million per population (Table 1). The average length of mapped reads for the Cape urchin samples was $229 \mathrm{bp}$, and the average base quality of the mapped reads was 35.1 Phred.

\section{Genome-wide variation}

The number of single nucleotide polymorphisms (SNPs) identified by PoPoolation v1.2.2 [47] varied among Granular limpet populations, with Port Nolloth having the lowest number of SNPs with 49,455 and Jacobsbaai having the highest with 152,423 (Table 1). The within-population average nucleotide diversity of the Granular limpet ranged from 0.009 to 0.012 for Tajima's $\pi$ and 0.010 to 0.013 for 
Table 1 The sample site, number of mapped reads (\# of mapped reads), number of SNPs calculated by PoPoolation (\# of SNPs), and genetic diversity indices (Tajima's $\pi$ and Watterson's $\theta_{W}$ ) are shown for the limpet, S. granularis and the urchin, $P$. angulosus. The number (\#) and percentage (\%) of private SNPs are also shown per population for both study species

\begin{tabular}{|c|c|c|c|c|c|c|c|}
\hline North to south orientation & Sample site & \# of mapped reads & \# of SNPS & Tajima's $\pi$ & Watterson's $\theta_{W}$ & \# of private SNPs & $\%$ of SNPs that are private \\
\hline \multicolumn{8}{|l|}{ S. granularis } \\
\hline \multirow[t]{5}{*}{ North } & PN & $3,372,943$ & 49,455 & 0.009 & 0.010 & 15,496 & 0.313 \\
\hline & $\mathrm{HB}$ & $4,263,248$ & 113,678 & 0.011 & 0.012 & 36,035 & 0.317 \\
\hline & $\mathrm{BB}$ & $4,756,683$ & 151,071 & 0.011 & 0.012 & 54,657 & 0.362 \\
\hline & LB & $3,674,168$ & 91,767 & 0.010 & 0.011 & 18,957 & 0.207 \\
\hline & $\mathrm{JB}$ & $4,613,158$ & 152,423 & 0.012 & 0.013 & 72,096 & 0.472 \\
\hline South & SP & $4,348,563$ & 135,499 & 0.011 & 0.012 & 57,630 & 0.425 \\
\hline \multicolumn{8}{|l|}{ P. angulosus } \\
\hline \multirow[t]{5}{*}{ North } & PN & $3,309,914$ & 100,849 & 0.011 & 0.012 & 62,007 & 0.615 \\
\hline & $\mathrm{HB}$ & $2,304,239$ & 18,682 & 0.006 & 0.007 & 6961 & 0.373 \\
\hline & BB & $3,234,311$ & 72,024 & 0.009 & 0.010 & 18,735 & 0.260 \\
\hline & LB & $3,133,465$ & 69,921 & 0.009 & 0.010 & 25,390 & 0.363 \\
\hline & $\mathrm{JB}$ & $4,436,171$ & 98,110 & 0.009 & 0.011 & 34,826 & 0.355 \\
\hline South & SP & $2,423,381$ & 24,747 & 0.007 & 0.008 & 8905 & 0.360 \\
\hline
\end{tabular}

Sample site abbreviations are as follows: SP Sea Point, JB Jacobsbaai, $L B$ Lambertsbaai, $B B$ Brandsebaai, $H B$ Hondeklipbaai, $P N$ Port Nolloth

Watterson's $\theta_{W}$ (Table 1). A total of 55,409 SNPs were identified with PoPoolation2 v1.201 [48] across all limpet populations, Port Nolloth again had the lowest number of SNPs, and Brandsebaai had the greatest (Table 2). As Popoolation2 is not capable of calculating diversity indices (i.e. Tajima's $\pi$ and Watterson's $\theta_{W}$ ), we calculated total heterozygosity from the GenePop files used in the outlier detection analyses. The total heterozygosity was highly similar between limpet populations, ranging between 0.082 to 0.084 (Table 2). The number of private SNPs (SNPs unique to certain locations) within the limpet populations ranged from 9 to 226, and the percentage of population-specific private SNPs ranged between $0.017 \%$ to $0.421 \%$ (Table 2 ).

The Cape urchin populations showed greater variation in the number of SNPs identified by PoPoolation, with the lowest $(24,747)$ for Sea Point and the highest $(100,849)$ for Port Nolloth (Table 1$)$. The populationspecific nucleotide diversity values, Tajima's $\pi$ and Watterson's $\theta_{W}$, ranged from 0.006 to 0.011 and 0.007

Table 2 The sample site, number of SNPs identified from all populations combined in Popoolation2 (\# of total SNPs), and the total heterozygosity $(\mathrm{Ht})$ are shown for S. granularis and P. angulosus. The number (\#) and percentage (\%) of those SNPs that were private are also shown for both species. Population abbreviations are provided in Table 1

\begin{tabular}{|c|c|c|c|c|c|c|}
\hline North to south orientation & Sample site & \# of mapped reads & \# of total SNPs & $\mathrm{Ht}$ & \# of private SNPs & $\%$ of SNPs that are private \\
\hline \multicolumn{7}{|l|}{ S. granularis } \\
\hline \multirow[t]{5}{*}{ North } & PN & $3,372,943$ & 47,090 & 0.082 & 35 & .074 \\
\hline & $\mathrm{HB}$ & $4,263,248$ & 53,686 & 0.084 & 226 & .421 \\
\hline & BB & $4,756,683$ & 54,862 & 0.084 & 15 & .027 \\
\hline & LB & $3,674,168$ & 52,352 & 0.084 & 9 & .017 \\
\hline & $J B$ & $4,613,158$ & 53,238 & 0.084 & 29 & .054 \\
\hline South & SP & $4,348,563$ & 53,003 & 0.082 & 42 & .079 \\
\hline \multicolumn{7}{|l|}{ P. angulosus } \\
\hline \multirow[t]{5}{*}{ North } & PN & $3,309,914$ & 6665 & 0.058 & 14 & .210 \\
\hline & $H B$ & $2,304,239$ & 5204 & 0.052 & 2 & .038 \\
\hline & BB & $3,234,311$ & 7775 & 0.054 & 2 & .026 \\
\hline & LB & $3,133,465$ & 7633 & 0.054 & 6 & .078 \\
\hline & $J \mathrm{~B}$ & $4,436,171$ & 7404 & 0.054 & 5 & .068 \\
\hline South & SP & 2,423,381 & 5625 & 0.057 & 2 & .036 \\
\hline
\end{tabular}


to 0.012 , respectively (Table 1 ). The more stringent criteria used in PoPoolation2 identified a total of 8,386 SNPs, and the within population number of SNPs ranged from 5,204 to 7,775 (Table 2). The number of private SNPs ranged from two to 14 SNPs, and the percentage of private SNPs ranged from $0.026 \%$ to $0.21 \%$ (Table 2 ). The total heterozygosity varied more between the Cape urchin populations compared to the limpet, with values ranging from 0.052 to 0.057 (Table 2). The Cape urchin showed considerably lower levels of population-specific diversity, with average heterozygosity being 0.055 and 0.083 respectively (Table 2).

The allele frequency spectrum plots showed minor differences in allele frequencies between populations when calculated from SNPs identified in Popoolation, and highly similar frequencies between populations when calculated from Popoolation2 SNPs (Additional file 1: Figure S1-S4).

\section{Detection of outlier loci}

A total of 55,409 SNPs from the Granular limpet populations were included in the outlier detection analyses. Bayescan analyses identified 98 outlier loci within the limpet populations, all of which identified as under diversifying selection. PCAdapt [49] selected a larger amount of outlier loci compared to Bayescan, with a total of 355 outliers. Only 34 outlier SNPs were detected by both Bayescan and PCAdapt, and the number of outliers within each population ranged from 14 to 30 (Table 3). Hondeklipbaai was the only location to have private outlier SNPs, with nine unique outlier loci. The 34 outliers chosen by both Bayescan and PCAdapt were located on 17 contigs.

Of the 17 contigs that were BLASTed, $76 \%$ of them successfully paired with sequences with an E-value of $10^{-5}$ or above. All matches were with hypothetical proteins from the Owl limpet, Lottia gigantea, genome and most were matched to conserved protein domains such as histone, homeodomain and ribonuclease $\mathrm{H}$-like

Table 3 The number of outlier SNPs identified in each limpet (S. granularis) and urchin (P. angulosus) population. Population abbreviations are provided in Table 1

\begin{tabular}{llll}
\hline $\begin{array}{l}\text { North to south } \\
\text { orientation }\end{array}$ & Sample site & \multicolumn{2}{l}{ Number of outlier SNPs } \\
\cline { 3 - 4 } & & S. granularis & P. angulosus \\
\hline \multirow{4}{*}{\begin{tabular}{l} 
North \\
\multirow{4}{*}{}
\end{tabular}} & PN & 14 & 7 \\
& HB & 30 & 5 \\
& BB & 16 & 8 \\
& LB & 15 & 8 \\
& JB & 16 & 8 \\
& SP & 19 & 8 \\
\hline
\end{tabular}

domains. (Additional file 1: Table S2). When outlier contigs were mapped to the L. gigantea genome to identify neighboring genes, the only non-hypothetical protein match was to the pol-like protein.

Of the 8,386 Cape urchin SNPs analyzed, 12 were selected as outlier loci by Bayescan, all of which were identified as under balancing selection. The PCAdapt outlier analysis identified a total of 61 outlier loci. Eight outlier loci were identified by both methods, with half of these outlier loci shared across all populations. Within the remaining half of outlier loci, three were found in all populations except in Hondeklipbaai, and one was found in all populations except for Port Nolloth. The eight outlier loci were located on seven contigs. Of the seven outlier contigs, four had BLAST results with significant E-values, and matched with predicted proteins from the Purple urchin, Strongylocentrotus purpuratus, genome (Additional file 1: Table $\mathrm{S} 2$ ). The respective domains of the predicted proteins included the histone $\mathrm{H} 3$, retroelements and mobile elements, and the Endonuclease/Exonuclease/Phosphatase family (Additional file 1: Table S2). When the four outlier contigs were mapped onto the $S$. purpuratus genome to identify neighboring genes, the only identified gene was the cysteine-rich motor neuron 1 protein precursor.

\section{Population genomic structuring}

The average pairwise $F_{\mathrm{ST}}$ values across all SNPs were similar between the two species. The values for the Cape urchin ranged from 0.006 to 0.019 , and the values for the Granular limpet ranged from 0.008 to 0.013 (Additional file 1: Tables S3 \& S4). The Cape urchin had a larger range of $F_{\mathrm{ST}}$ values per locus, with a minimum $F_{\mathrm{ST}}$ of $2.1 \mathrm{e}^{-5}$ and a maximum $F_{\mathrm{ST}}$ of 0.951 , compared to the minimum and maximum per locus $F_{\mathrm{ST}}$ values of $2.3 \mathrm{e}^{-5}$ and 0.785 for the Granular limpet.

To assess population genomic structuring, we first removed the outlier SNPs to calculate 'neutral' pairwise $F_{S T}$ values. We subsequently calculated 'outlier' $F_{S T}$ values using only the outlier SNPs. The genomic differentiation patterns based on $F_{\mathrm{ST}}$ values from the neutral SNPS differed from those based on outlier SNPs for both species (Fig. 2). Interestingly, the populations within the mid-coast (i.e. Jacobsbaai, Lambertsbaai, and Brandsebaai) tended to cluster together for both species, for both non-outlier and outlier loci (Fig. 2). Furthermore, the population of Hondeklipbaai was genomically distinct in both the neutral and outlier analyses for both study species (Fig. 2).

Both species showed no signals of isolation-by-distance (IBD), based on the full SNP datasets, as well as neutral and outlier SNP datasets (Additional file 1: Table S5). The K-means clustering analyses with fastStructure v1.0 [50] 

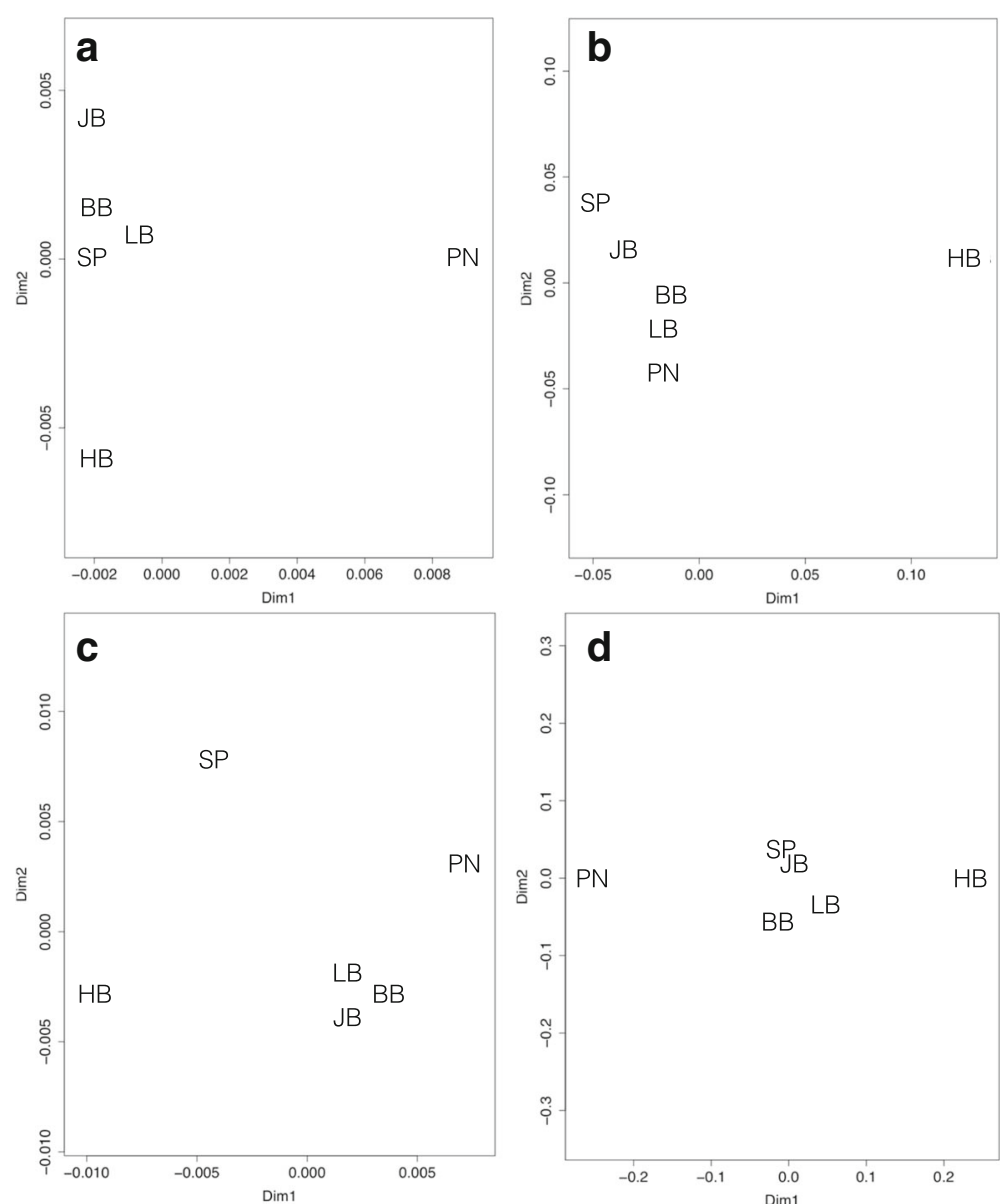

Fig. 2 Genetic differentiation displayed in PCoA plots, calculated from non-outlier SNPs (a, c) and outlier SNPs (b, d) for the limpet, S. granularis $(\mathbf{a}, \mathbf{b})$ and the urchin, $P$. angulosus $(\mathbf{c}, \mathbf{d})$ populations. Population abbreviations are provided in Table 1

resulted in wide ranges of $\mathrm{K}$ values for the neutral and outlier datasets for both species and the admixture plots did not display strong signals of structure (data not shown).

\section{Discussion}

The South African west coast harbors highly productive coastal communities $[41,50]$, but is also widely impacted by anthropogenic development [27]. It is thus vital to understand the genomic patterns and adaptive potential of marine organisms inhabiting this region, because even basic population genetic metrics have been shown to play important roles in conservation planning [42, 51, 52]. The region is also of interest as, compared to other studies that have identified genome-wide variation [14-16, 53-55], it does not experience strong environmental heterogeneity, and so all else being equal, populations within this area might be expected to have fewer signals of local adaptation $[56,57]$.

Using a high-throughput sequencing approach, we constructed SNP datasets and identified loci that appear to be under selection for two non-model rocky shore species within this region. In line with our predictions, we found relatively low numbers of outlier SNPs within each species, and identified outlier genes associated with different selective pressures than those previously identified in marine taxa occurring in regions with larger environmental gradients [11-16]. We also found differences in outlier SNP patterns between the two species (Fig. 2), possibly due to different selective forces acting on high and low shore microhabitats, or because the species have found different pathways to deal with environmental stressors [58, 59]. Our findings show that within a relatively homogeneous environment, there are species-specific signals of selection, highlighting the importance of localized environmental and ecological forces potentially shaping species' evolutionary trajectories. These findings promote using SNP datasets for conservation purposes to identify populations with heightened adaptive potential, even across relatively homogenous habitats, as these methods can elucidate areas with unique selective pressures with greater power than traditional markers $[5,7,60]$. 
Pool-seq analyses and their implications for SNP calling and patterns of genomic variation

For each study species, the pattern in number of SNPs (identified by PoPoolation and PoPoolation2) generally follows that of the number of mapped reads (Tables 1 and 2), which suggests that the number of mapped reads per population influences the number of total SNPs per population. Further, the metrics calculated by PoPoolation all follow the same pattern as the number of SNPs and number of mapped reads (Table 1), indicating that population-specific parameters are potentially biased by the number of mapped reads and SNP coverage. However, the metrics calculated from all populations combined in Popoolation2 do not follow the same pattern as the number of mapped reads or number of SNPs (Table 2). Further, the allele frequency spectrum plots display less variation in allele frequencies for the Popoolation2 results (Additional file 1: Figure S1-S4), which also suggests that the strict resampling to even coverage across all populations in Popoolation2 led to less biased results. Therefore, the metrics derived from all populations combined are less likely to be influenced by methodological artifacts, and probably reflect actual biological processes. Given the uncertainty around potential biases associated with the population-specific calculations, the remainder of this article only refers to Popoolation 2 results when discussing the genomic variation of the study species.

The number of SNPs per population varied both within and between species, and show noticeably more SNPs in the Granular limpet populations compared to the Cape urchin (average number of SNPs per population being 52,000 and 6,700 were SNPs respectively; Table 2). This finding, in conjunction with higher levels of heterozygosity in the limpet populations (Table 2), is somewhat unexpected as there is ample evidence that urchin species harbor highly polymorphic individuals [61-63]. However, the interspecific difference in the number of SNPs is likely caused by the Granular limpet having a higher number of raw sequences, a longer average length and higher average quality of mapped reads [64]. For example, the average number of paired reads is 5.9 million for the limpet and 4.5 million for the urchin, plus the limpet samples have a total of 25 million mapped reads compared to the 19 million for the urchin (Table 1). Given that the number of raw sequences and mapped reads in turn affects the number of identified SNPs [64], it is difficult to compare SNP diversity between species.

Our results are of further interest, as the Cape urchin has a longer de novo reference sequence, and higher mean coverage than the Granular limpet, yet fewer total SNPs are recovered throughout the urchin populations in comparison (8,386 vs 55,409 SNPs). This result is most likely a consequence of the Cape urchin having more variation between populations than the Granular limpet. For example, the difference in the number of reads per population is 2.1 million reads for the urchin and 1.3 million reads for the limpet, whilst the difference in mean coverage is 149 and 59, respectively. As the total number of SNPs is calculated from all populations combined, if a SNP does not have sufficient coverage in at least one population, that SNP will be excluded from the overall count, which could explain the lower number of total SNPs in the urchin populations.

It should also be acknowledged that the patterns of genome-wide SNP variation may be influenced by ascertainment bias, which is when a selection of markers (usually those with high minor allele frequencies) affect inferences of the larger population, which is a problem experienced in many SNP analyses [65]. However, RADseq approaches are thought to have more unbiased population statistics due to higher number of sequenced genomic regions [66]. Furthermore, our large pool sizes and stringent SNP filtering protocols should also decrease the possible effects of ascertainment bias.

There is also the possibility that interspecific sequencing differences are influencing the de novo assemblies. One would expect the Cape urchin to have a larger de novo assembly, as the annotated genome for its respective taxonomic group (the Purple urchin, S. purpuratus, [67]), is $454 \mathrm{Mb}$ larger than that of the Granular limpet (the Owl limpet, L. gigantea, [68]), yet our results show de novo assembly sizes to be similar between the two species. Molluscs are, in general, known to have a wider range of genome sizes than echinoderms, with sizes ranging from around $390 \mathrm{Mb}$ to $5770 \mathrm{Mb}$, compared to $290 \mathrm{Mb}$ to $4300 \mathrm{Mb}$ [69]. The species in our study most likely show similar de novo assembly sizes due to the enzymatic activity of RAD-seq, which will result in similar sizes of raw reads, hence resulting in similar $\mathrm{K}$ values for the de novo assembly [70]. The DNA quantity ( $\sim 29$ and $\sim 30 \mathrm{ng} / \mu \mathrm{l})$ and quality $(\sim 32$ and $\sim 33$ Phred scores $)$ of the original pooled samples are also similar between species, which could have implications for de novo assembly sizes, yet a more in-depth analysis of the effects of quantity and quality of pooled samples on de novo assemblies is needed to address this theory.

While several studies suggest that Pool-seq provides accurate estimates of genomic variation [71-73], other studies express concerns about Pool-seq limitations and biases, and subsequently calls have been made for the standardization of a Pool-seq bioinformatics pipeline to increase the reliability of Pool-seq results [74, 75]. As Pool-seq is becoming more popular in genomic studies [76], it is important to understand the effects of differential amounts of genomic information per pool on diversity metrics, given the potential impacts applying these data in the management or conservation of natural resources. 


\section{A comparative approach to identify areas of evolutionary} uniqueness

The number of private SNPs across populations of both species show a non-geographical gradient (Table 2), suggesting that neither IBD, nor the regional oceanographic features, are likely driving the observed pattern. The IBD tests also show no significant isolation-by-distance from either the neutral or outlier datasets of either species (Additional file 1: Table S5). As the number of private SNPs is expected to be driven by gene flow and genetic drift rather than other evolutionary processes such as mutation and selection [77], we can assume that populations with high levels of private SNPs are demographically isolated to some degree.

Overall, the results from the private SNPs suggest that the northern populations, Port Nolloth and Hondeklipbaai, are evolutionarily unique with regards to the study species (Table 2). This finding could mean that these populations are experiencing environmental pressures either preventing SNPs from spreading to surrounding areas or selecting against SNPs from other populations. Another possible explanation for the uniqueness of this area is the occurrence of range expansions and associated population growth due to sea-level changes in the past 100,000 years, which might have facilitated previously isolated populations being re-integrated into the west coast meta-population [78]. Species distribution models based on paleoclimate temperature data of the Last Glacial Maximum (LGM; Seymour, Midgley \& von der Heyden, pers. comm) suggest that west coast marine species shifted their ranges south, and that coastal marine species would have been locally extinct north of Jacobsbaai, with a subsequent range expansion northwards as sea levels and temperatures increased. Regardless of the processes that have shaped the array of private SNPs within the study species, our results indicate that the northern west coast of South Africa may possibly be a reservoir of genomic diversity for marine invertebrates not found elsewhere.

\section{Fine-scale phylogeographic patterns suggest complex evolutionary histories}

The study species show different patterns of genomic variation and differentiation, providing further evidence that the evolutionary processes shaping marine biodiversity in South Africa are complex (Fig. 2; [79, 80]). For example, neither species shows a geographically ordered pattern in genomic differentiation (Fig. 2), which is observed for other marine invertebrates within the region $[35,37]$. For both species, the genomic structuring differs between non-outlier loci and outlier loci (Fig. 2), which is expected as outlier loci are identified from their unique $F_{S T}$ values. Increased genetic structuring in outlier loci has been discovered for other high gene flow marine species, most of which is attributed to historical population processes and local adaptation [14, 81-83]. However, outlier analyses are not without theoretical complications, often suffering from high rates of false positives [84]. In our case, the low levels of population structuring in our SNP datasets provide a less noisy neutral background for outliers to be detected from, making our outlier analyses more robust [85].

It is noteworthy that the genomic structuring of outlier loci for both species show Hondeklipbaai as being highly differentiated (Fig. 2), which suggests this finding is not due to chance alone. Of the Cape urchin populations, Port Nolloth and Hondeklipbaai are highly differentiated in outlier loci (Fig. 2), which is interesting as they are geographically close to one another. The high genomic distinctiveness of the northernmost populations could be due to local selection pressures acting on these populations [86], or from both species experiencing a recent expansion into this region, which would cause allele frequencies of all loci, including those selected on, to be different from the rest of the meta-population [87, 88]. At present, we can assume that the northern populations of both species have unique evolutionary histories, which makes them priority areas for the conservation of evolutionary processes.

With the K-means clustering analyses, we found no clear signal of population structure for both species, which contradicts previous structure analyses with mtDNA cytochrome oxidase I, where the Cape urchin displayed high levels of population structuring [35, 42]. Several environmental and biological features are probably shaping the shallow genetic structure of our study species, such as recent changes in demography or the strongly northward flowing Benguela Current and inshore eddie systems [89], although these are poorly understood for nearshore coastal environments [90]. Numerous phylogeographic studies have invoked life history traits as drivers of genetic structuring in marine species [83, 91, 92], however, our study species have notably different life history traits, with, PLD at roughly 50 days for the urchin and 10 days for the limpet [37]. There has been ample debate on life history traits as predictors of population structuring of marine invertebrate species, [93, 94], and hopefully a clearer picture will arise as more comparative genomic phylogeographic studies are conducted.

\section{Identifying functions of outlier loci}

Even though there are generally low levels of genomewide differentiation between populations for both species (Additional file 1: Tables S3 \& S4), there are loci displaying significantly high levels of differentiation, classifying them as having a higher probability of being actively selected on. Of the outlier loci for each species, approximately $76 \%$ significantly match to the Owl limpet, L. gigantea genome and $57 \%$ significantly match that of the Purple urchin, $S$. 
purpuratus. Fewer significant BLAST results for the Cape urchin are most likely owing to the high levels of polymorphism in urchin genomes [61-63].

Between the two species, four contigs containing outlier loci had high probabilities of being related to histone proteins (Additional file 1: Tables S2). It is possible that the identification of histones as outlier loci could be a result of genetic hitchhiking [95], or due to histones being highly conserved, therefore making their identification far easier than rare or undescribed proteins. While histone variants are known to modify gene expression patterns within organisms [96, 97] few studies have investigated the influences of histone methylation on the adaptation of marine organisms [98], although histone loci have been proven to be diagnostic for sister species in recently diverged corals $[99,100]$. Urchins are also known to have a large family of histone genes compared to other invertebrate species [101, 102]. Further, Zbawicka and co-authors [103] report four out of 20 outlier loci as histone genes within Mytilus trossulus and Mytilus edulis in the Baltic Sea. Ultimately, further investigation is needed to better understand the potential functional roles of histone variants within marine invertebrates to be able to state their adaptive significance within our study.

In addition to histone variants, both species displayed outlier-containing contigs matching to sequences within the Endonuclease/Exonuclease/Phosphatase family, and more specifically, to reverse transcriptases and mobile elements within this domain, which is not unusual as retrotransposons and retroelements are thought to be widespread throughout eukaryotic genomes [104, 105]. Retroelements are highly mobile genetic elements that are known to play significant roles in disease progression, stress reactions and embryogenesis, and are thought to be found in regions of the genome with reduced rates of recombination [106, 107]. Genes within these domains have been matched to outlier loci in previous genomic studies of other marine invertebrates [97, 108], however, the authors of these studies conclude that this finding is not a result of the annotated sequences not being under selection themselves, but rather linked to loci that are under putative selection.

The remaining contigs were matched to proteins of various domains and functions, including alpha tublins, ribonuclease $\mathrm{H}$-like enzymes, homeodomain proteins, cadherins, and DNA breaking-rejoining enzymes. Most of these protein domains are either highly abundant throughout mollusc and echinoderm genomes and/or are highly conserved [109-111], and therefore are also likely not under selection themselves but again linked to genes under selection.

The only identified neighboring genes of the outlier loci were the pol-like protein of the L. gigantea genome and the cysteine-rich motor neuron 1 protein precursor of the S. purpuratus genome. The pol-like protein has been identified in outlier analyses of other marine invertebrates [112-114], and is expected to be involved with immunity and stress relief [115]. The cysteine-rich motor neuron 1 protein precursor is not commonly identified as a candidate gene, but has displayed differential expression in the sea cucumber Apostichopus japonicas [116]. The cysteine-rich motor neuron protein is predicted to assist with the development of the central nervous system by interacting with growth factors involved with motor neuron differentiation and survival [117]. Ultimately, further annotation of related genomes and more indepth seascape genomic studies are required to further test the effects of environmental pressures on the Cape urchin and Granular limpet along the South African west coast.

\section{Comparative genomics: Local selective forces within a homogeneous environment}

Notably, our study recovered different patterns from the spatial distribution of outlier loci, with $\sim 24 \%$ shared by all limpet populations, but $50 \%$ shared by all urchin populations. Furthermore, the urchin populations have no private outlier loci, compared to the nine private outlier loci shown in the limpet samples. For the urchin, the high number of shared outlier SNPs could be caused by selection on standing genetic variation, high $\mathrm{N}_{\mathrm{e}}$ or rather by the 'transporter-hypothesis', where gene flow spreads favorable adaptations between populations [118]. Our finding of high levels of shared outliers contradicts the results of Ravinet and co-authors [17] who found no shared outlier loci between three $L$. saxatilis populations within $10 \mathrm{~km}$ of each other. However, the authors attributed these results to either recent de novo mutations causing parallel evolution, unique selection pressures between sample locations generating non-shared outliers or complex polygenetic traits being responsible for similar phenotypes.

While most outlier loci are shared between at least two limpet populations, some outliers are private (Table 3), with Hondeklipbaai in particular having both the highest number of outlier and private outlier loci. Interestingly, the same population, Hondeklipbaai, has the lowest number of outlier and private outlier loci out of the urchin populations. This sample site has high levels of copper deposits in local sands [119], and copper exposure has been shown to be a strong selective agent within other marine organisms [120-122], but unfortunately, the lack of an annotated genome precludes a solid explanation.

It is likely that some of the differences in genomic variation reflect the unique ecological, biological and historical differences between the two study species. For example, although we sampled individuals from the 
same site, the species differ in their location on the rocky shore; the Granular limpet occurs higher on the shore where animals experience longer periods of emergence and hence more local environmental heterogeneity [123]. In contrast, the Cape urchin remains submerged in tidal pools, which might buffer factors such as rapid temperature changes and desiccation [123].

Our findings are not unexpected, as previous studies focusing on the adaptive traits of the periwinkle Littorina saxatilis [17, 25] found evidence of divergent selection between high and low shore ecotypes. In addition, Dong and Somero [124] compared the enzymatic activity of $\mathrm{NADH}$ dehydrogenase across six marine snail species within the Lottia genus and found that high shore species performed better at higher temperatures compared to those inhabiting the low-shore. Further, Galindo and co-authors [97] identified outliers associated with shell matrix, muscle and metabolic proteins (including NADH dehydrogenase) and reverse transcriptases from $L$. saxatilis individuals within either the high- or mid-shore ecotypes. Overall, it is likely that micro-environmental and ecological differences associated with variables such as temperature, exposure to wave action, competition and predation, play significant roles in shaping the outlier SNP patterns within the Granular limpet populations on the South African west coast.

As the Cape urchin is only found within the low-shore, and is known to protect itself from increases in air temperature and wave pressure by inhabiting sheltered rock pools [123], it is likely that the outlier SNPs found within this species are responding to environmental variables on a larger scale, such as $\mathrm{CO}_{2}$ and chlorophyll concentrations or SST, all of which have been identified as features shaping genetic diversity patterns in other urchin and marine species [125-128]. Furthermore, numerous studies have invoked SST as a strong determinant of driving genetic variation seascapes [11, 14, 81, 129]. In fact, several candidate genes putatively under selection are associated with changes in temperature in marine invertebrates, with many studies indicating that genes related to energy metabolism play important adaptive roles in changing temperature regimes [130-133]. We did not anticipate this to be a prominent selection force, as the South African west coast does not display a strong SST gradient [26], and accordingly to our predictions, no putatively selected loci associated with metabolic pathways were identified. It should be noted, however, that not all SNPs were matched to known genomic regions, which leaves uncertainty regarding which environmental or biological features are mostly responsible for the genomic patterns observed. Ultimately, it is most likely that there are additive or synergistic, rather than single, environmental and ecological processes shaping the evolutionary dynamics of marine taxa [134], including our study species.

\section{Conclusions}

This is the first study to utilize a pooled RAD-seq approach to conduct comparative phylogeographic analyses, make inferences about population-based dynamics, and understand the evolutionary forces driving both intra- and inter-specific patterns of adaptive potential. It should be noted that this is a preliminary approach to properly identifying candidate genes for adaptation for conservation purposes, as the outlier loci and their functional roles still need to be confirmed and tested for both species. However, we can still make inferences about intraspecific population dynamics and adaptive potential with greater power with genome-wide SNP markers, which would not be possible with only a limited number of loci using traditional marker types. We detect signals of population differentiation and selection, suggesting that selective forces are acting on localized scales. Another interesting finding is that the two northernmost populations are genomically unique for both species, which is significant as it suggests that local environmental or ecological features are shaping the evolutionary trajectories of multiple coastal invertebrate species, even within this relatively environmentally homogeneous area. This preliminary finding provides a backdrop for a more in-depth seascape genomic analysis, which could help elucidate the possible environmental forces driving the genetic differentiation of marine invertebrates inhabiting these sites.

Our study also indicates that the Pool-seq methodology with de novo assemblies may be susceptible to differences in data quality. We argue that if Pool-seq is to be effective in comparing genetic diversity between nonmodel species, additional Pool-seq specific bioinformatic developments are required $[47,48,135,136]$. We also found diverse patterns of selection between species, which supports the use of next generation sequencing techniques to carry out comparative phylogeography studies to assess the drivers of evolutionary processes of whole communities instead of single species.

Finally, we found evidence of differential selection among rocky shore sites, which suggests that environmental gradients within these microhabitats are also strong drivers of evolutionary change [18]. The complex patterns of private and outlier SNPs, both within and between species, suggests that studies aimed at identifying genomic variation with SNP datasets should not only focus on single species within predominantly heterogeneous environments, but also across different species and in seemingly homogeneous regions.

\section{Methods}

Study species and sampling protocol

The focal species were selected due to their high abundance within the high (Granular limpet; S. granularis) and low-mid (Cape urchin; P. angulosus) shores [39], as 
well as their highly differentiated genetic patterns within the study region (based on COI). Samples were collected from six rocky intertidal localities along the west coast of South Africa (Fig. 1) during the period of June to August 2015. Forty samples of both species were collected from each site and stored in $100 \%$ ethanol. The individuals from each of the six sample locations were labeled as separate 'populations'.

Twenty-five micrograms of tissue were taken from each sample (gonad tissue from the urchin, foot tissue from the limpet). Genomic DNA was extracted using Qiagen DNeasy Blood \& Tissue kit following the manufacturer's protocols and extractions were then stored at $-20{ }^{\circ} \mathrm{C}$. At least $3 \mu \mathrm{g}$ of high molecular weight DNA was measured into a concentration of $40 \mathrm{ng} / \mu \mathrm{l}$ using molecular grade $\mathrm{H}_{2} 0$. For each species, all 40 individuals from each location were equimolarly pooled to create a total of 12 samples for Illumina sequencing. The pooled samples were flash frozen and sent to the Hawaii Institute of Marine Biology for library preparation [137] and v3 $2 \times 300 \mathrm{PE} \mathrm{Mi-Seq} \mathrm{Illumina} \mathrm{sequencing} \mathrm{through} \mathrm{the}$ Genetics Core Facility (GCF).

\section{DNA digestion and library preparation}

Estimates of genetic variation are becoming more robust with the emergence of high-throughput sequencing methods, such as RAD-seq [138-141]. RAD-seq provides a relatively low-cost and efficient method to characterize SNPs over the entire genome, and is increasingly utilized to obtain genomic information from non-model organisms [142, 143]. Yet, because the cost of sequencing many individuals from multiple sites is often prohibitive, many studies apply a pooled sequencing (Pool-seq) approach, in which DNA from multiple individuals are combined and sequenced as a whole population [144, 145]. While Pool-seq does not allow individuals to be identified and compared within a population, it does allow for more individuals to be analyzed, which increases the power to estimate population-based allele frequencies $[144,146]$, and has been shown to be a viable approach to identify population genomic variation and detect local adaptation [145].

We employed a pooled ezRAD library preparation and sequencing approach [46], which uses a high-frequency restriction enzyme to fragment the DNA and obtain a reduced-representation sequencing library. For digestion and library preparation, we followed protocols described by Knapp and co-authors [137]. The size-selected DNA was prepared for sequencing using the KAPA Hyper Prep kit. Fragment size for the libraries was established using a bioanalyzer and quantified using qPCR as quality control measures before sequencing on the Illumina MiSeq platform.

\section{De novo assembly and data processing}

The quality of raw reads from the MiSeq facility was first assessed with the FASTQC toolkit [147]. The reads were then trimmed with Trim Galore! (https://www.bioinformatics.babraham.ac.uk/projects/trim_galore/), trimming adapter and overrepresented sequences, as well as sections with bases having a Phred quality score lower than 20. As optimizing k-mer lengths for RAD sequences produces the highest quality assemblies [140] we conducted a de novo assembly with Spades v.3.5.0 [148] testing multiple $\mathrm{k}$-mer lengths, and determined optimal k-mer lengths of 81 for the Cape urchin and 91 for the Granular limpet. Assembly statistics, such as assembly length, longest contig, and N50 and L50 lengths were calculated with QUAST v4.1.1 [149].

As semi-global alignment and realignment of unmapped reads is recommended for pooled samples [140], we used BWA-MEM [150], following the same parameters as in Toonen et al. [46], to map the filtered reads onto the de novo reference sequences. Mapping results (number of mapped versus unmapped reads) were calculated using the 'stats.idx' command in SAMtools v.1.3 [151]. The resulting SAM files were converted to BAM files with SAMtools, undergoing further filtering to discard all reads not mapped in a proper pair, reads not in a primary alignment and reads with a mapping quality score under 20 . The BAM files were sorted and indexed, and then used to call variants with the 'mpileup' command in SAMtools, using a minimum quality score of 20 and maximum depth of 1000 reads per locus.

\section{Estimating population genomic variation}

The population-specific number of SNPs, nucleotide diversity (Tajima's $\pi$ ) and population mutation rate (Watterson's $\theta_{W}$ ), were calculated for each population using the 'variance-sliding' command in PoPoolation [47]. The population specific number of SNPs, $\pi$, and $\theta_{W}$ were all calculated using a sliding window of 1,000 base pairs (bp), which was chosen after testing windows of 100,500 and $1,000 \mathrm{bp}$. To standardize for sequencing biases, we subsampled for uniform coverage (minimum coverage of 10 and maximum coverage of 200) and set a minimum count (i.e. the number of times the allele appears) of four and a quality score of 20.

As the above-mentioned metrics were all calculated from pileup files containing only SNPs found within each individual population, we also wanted to calculate the number of SNPs per population from all samples combined. To do this, the mpileup file was converted in PoPoolation2 [48], producing a sync file indicating allele counts across all populations. The number of total SNPs and number of private SNPs were then identified from the allele counts given by the 'snp-frequency-diff' command in PoPoolation2. As these metrics are derived 
from all populations combined, to account for the increase in reads we increased the minimum count to eight, the minimum coverage to 40 , and the maximum coverage to 500 to call SNPs at this stage. As Popoolation2 is not capable of calculating diversity indices such as Tajima's $\pi$ and Watterson's $\theta_{W}$, total heterozygosity was calculated from the GenePop file used to detect outliers (see section below) using Genodive [152].

To assess the effects of population-specific resampling on intraspecific variation, we compared the frequencies of SNPs calculated by both Popoolation and Popoolation2. As allele frequencies are not available for Poolseq, we used the allele count over allele coverage to represent allele frequencies.

\section{Detection of selection footprints}

Given the uncertainty around RAD-seq, Pool-seq, and outlier detection methods in general [153-155], we followed the current trend in the literature and applied multiple outlier analyses to detect potential outlier loci with increased stringency. To identify outlier loci, we first converted the sync files created in PoPoolation2 to GenePop files, using the PoPoolation2 command 'subsample sync2GenePop'. This step underwent the same filtering as the 'snp-frequency-diff' command, with a minimum allele count of eight, minimum coverage of 40 , maximum coverage of 500, as well as a target coverage of 40 to best simulate a GenePop file from 40 individually genotyped individuals. GenePop files were further edited using custom Perl script, to merge all contigs and identify locus positions.

The edited GenePop files were converted into Bayescan files using PGDSpider2 v2.1.03 [156]. The first outlier detection method, Bayescan v.2.1 [157], was run with 20 pilot runs, 10,000 iterations and a burn-in of 50,000, and 55,000 reversible-jump MCMC chains, using a prior odds value of 1,000 , a thinning interval of 10 and a false discovery rate (FDR) of 0.05 . The second approach, PCAdapt, was used to detect outlier loci based on principal component analyses [49]. Input files were created from the allele counts file produced by the 'snp-frequency-diff' command in PoPoolation2. Six principal components were used for both species, and outliers were identified as loci with a qvalue lower or equal to 0.05 .

To evaluate the functional roles of the outlier loci that were chosen by both methods, the contigs associated with each outlier locus were subject to BLASTX searches, using the non-redundant protein sequences database and an E-value cut off of $10^{-5}$ [158]. To identify neighboring genes of the outlier loci, we aligned the outlier contigs onto the annotated genomes of L. gigantea and S. purpuratus, then BLASTed the flanking regions within $2 \mathrm{~KB}$ of either side of the contig, using the same mapping and search parameters listed above.

\section{Estimating genomic population structuring}

Genetic population structure was characterized by pairwise $F_{\mathrm{ST}}$ values calculated by the 'sliding-fst' command in PoPoolation2, using a minimum count of eight and coverage of 40 and a maximum coverage of 500 . To visualize the genomic differentiation between the populations for each species, we created Principal Coordinates Analysis (PCoA) plots based on the average pairwise $F_{\mathrm{ST}}$ values for both the putatively neutral (excluding outlier) and selected (outlier) SNPs using the vegan package in R-studio [159]. To evaluate genetic structure, we ran K-means clustering analyses separately on the neutral and outlier datasets with fastStructure v1 [160]. For each dataset, we tested K values from one to ten, with the prior parameter set to both 'simple', with the seed parameter set to 100 . To test for isolation-by-distance, we performed Mantel tests with logtransformed geographic distances between sample locations and linearized $F_{S T}$ values $\left[F_{S T} /\left(1-F_{S T}\right)\right]$, using the vegan package in $\mathrm{R}$. We ran three types of Mantel tests (Pearson, Spearman, and Kendall) on the full, and putatively neutral, and selected datasets for each species.

\section{Additional file}

Additional file 1: Tables S1 - S5 and Figure S1 - S4 as referred to in the text. (DOCX $1086 \mathrm{~kb})$

\section{Abbreviations}

COI: Cytochrome oxidase I; IBD: Isolation by distance; LGM: Last glacial maximum; mtDNA: Mitochondrial DNA; $\mathrm{N}_{\mathrm{e}}$ : Effective population size; PLD: Pelagic larval duration; RAD: Restriction site associated DNA; SNP: Single nucleotide polymorphism; SST: Sea surface temperature

\section{Acknowledgements}

SvdH thanks Stellenbosch University for a Discretionary Grant, as well as the National Research Foundation of South Africa for Grant 92788 awarded through the Competitive Support for Rated Researchers. ESN was partially supported by a NRF Freestanding Masters Scholarship. BG was supported by the CAS Pioneer Hundred Talents Program. ESN would also like to acknowledge the CAF at Stellenbosch University and specifically Charl Moller for his assistance with the Stellenbosch University HPC. RJT and ISSK were supported by the National Science Foundation NSF-OA\#1416889.

\section{Funding}

This research was supported by a National Research Foundation grant (92788), and a National Science Foundation grant (1416889).

\section{Availability of data and materials}

DNA sequences: Genbank accessions SAMN07685852-SAMN07685863; NCBI SRA: SUB3067817.

Sampling locations and meta-data: GeOME: http://n2t.net/ark:/21547/Aqx2

\section{Authors' contributions}

EN and SvdH conceived the study. EN carried out sampling, laboratory work and analyzed the data. IK constructed the libraries and both BG and RT provided help with analyses. EN and SvdH drafted the manuscript with significant inputs from $\mathrm{RH}, \mathrm{BG}, \mathrm{IK}$ and $\mathrm{RT}$, who contributed towards interpretation of results and writing. All authors have read and approved the manuscript. 


\section{Ethics approval and consent to participate}

Samples were collected under a permit (RES2015/26) issued by the Department of Agriculture, Forestry and Fisheries, South Africa.

\section{Competing interests}

The authors declare that they have no competing interests.

\section{Publisher's Note}

Springer Nature remains neutral with regard to jurisdictional claims in published maps and institutional affiliations.

\section{Author details}

'Evolutionary Genomics Group, Department of Botany and Zoology, University of Stellenbosch, Private Bag X1, Matieland, 7602, South Africa. ${ }^{2}$ Hawai'i Institute of Marine Biology, School of Ocean and Earth Science and Technology, University of Hawai'i at Mānoa, Kāne'ohe, HI 96744, USA. ${ }^{3}$ The Key Laboratory of Zoological Systematics and Evolution, Institute of Zoology Chinese Academy of Sciences, Beijing 100101, China.

\section{Received: 21 November 2017 Accepted: 23 April 2018}

\section{Published online: 09 May 2018}

\section{References}

1. Hart MW, Marko PB. It's about time: divergence, demography, and the evolution of developmental modes in marine invertebrates. Integr Comp Biol. 2010;50:643-61.

2. Marko PB, Hart MW. The complex analytical landscape of gene flow inference. Trends Ecol Evol. 2011;26:448-56.

3. Pecl GT, Araújo MB, Bell JD, Blanchard J, Bonebrake TC, Chen IC, et al. Biodiversity redistribution under climate change: Impacts on ecosystems and human well-being. Science. 2017;355:eaai9214.

4. Loeschcke V, Tomiuk J, Jain SK. Conservation genetics. Boston, Berlin: Birkhäuser. 2013

5. Funk WC, McKay JK, Hohenlohe PA, Allendorf FW. Harnessing genomics for delineating conservation units. Trends Ecol Evol. 2012;27:489-96.

6. Narum SR, Buerkle AC, Davey JW, Miller MR, Hohenlohe PA. Genotyping-bysequencing in ecological and conservation genomics. Mol Ecol. 2013;22:2841-7.

7. Shafer $A B$, Wolf JB, Alves $P C$, Bergström L, Bruford MW, Brännström I, et al. Genomics and the challenging translation into conservation practice. Trends Ecol Evol. 2015:30:78-87.

8. Baird NA, Etter PD, Atwood TS, Currey MC, Shiver AL, Lewis ZA, et al. Rapid SNP discovery and genetic mapping using sequenced RAD markers. PLoS One. 1998:3:e3376.

9. Schmidt PS, Serrão EA, Pearson GA, Riginos C, Rawson PD, Hilbish TJ, et al. Ecological genetics in the North Atlantic: environmental gradients and adaptation at specific loci. Ecology. 2008;89:91-107.

10. Lexer C, Wüest RO, Mangili S, Heuertz M, Stölting KN, Pearman PB, et al. Genomics of the divergence continuum in an African plant biodiversity hotspot: drivers of population divergence in Restio capensis (Restionaceae). Mol Ecol. 2014;23:4373-86

11. Bradbury IR, Hubert S, Higgins B, Borza T, Bowman S, Paterson IG, et al. Parallel adaptive evolution of Atlantic cod on both sides of the Atlantic Ocean in response to temperature. Proc R Soc Lond B Biol Sci. 2010;277: 3725-34.

12. Renaut S, Nolte AW, Rogers SM, Derome N, Bernatchez L. SNP signatures of selection on standing genetic variation and their association with adaptive phenotypes along gradients of ecological speciation in lake whitefish species pairs (Coregonus spp.). Mol Ecol. 2011;20:545-59.

13. Bourret V, Kent MP, Primmer CR, Vasemägi A, Karlsson S, Hindar K, et al. SNP-array reveals genome-wide patterns of geographical and potential adaptive divergence across the natural range of Atlantic salmon (Salmo salar). Mol Ecol. 2013;22:532-51.

14. Milano I, Babbucci M, Cariani A, Atanassova M, Bekkevold D, Carvalho GR, et al. Outlier SNP markers reveal fine-scale genetic structuring across European hake populations (Merluccius merluccius). Mol Ecol. 2014;23:118-35.

15. Guo B, DeFaveri J, Sotelo G, Nair A, Merilä J. Population genomic evidence for adaptive differentiation in Baltic Sea three-spined sticklebacks. BMC Biol. 2015;13:19-37.

16. Guo B, Li Z, Merilä J. Population genomic evidence for adaptive differentiation in the Baltic Sea herring. Mol Ecol. 2016;25:2833-52.
17. Ravinet M, Westram A, Johannesson K, Butlin R, André C, Panova M. Shared and nonshared genomic divergence in parallel ecotypes of Littorina saxatilis at a local scale. Mol Ecol. 2016;25:287-305.

18. Wagner DN, Baris TZ, Dayan DI, Du X, Oleksiak MF, Crawford DL. Fine-scale genetic structure due to adaptive divergence among microhabitats. Heredity. 2017;11:594-604.

19. Avise JC. The history and purview of phylogeography: a personal reflection. Mol Ecol. 1998;7:371-9.

20. Bowen BW, Gaither MR, DiBattista JD, lacchei M, Andrews KR, Grant WS, et al. Comparative phylogeography of the ocean planet. Proc Natl Acad Sci U S A. 2016;113:7962-9.

21. Riddle BR. Comparative phylogeography clarifies the complexity and problems of continental distribution that drove AR Wallace to favor islands. Proc Natl Acad Sci U S A. 2016;113:7970-7.

22. Toonen RJ, Andrews KR, Baums IB, Bird CE, Concepcion GT, Daly-Engel TS, et al. Defining boundaries for ecosystem-based management: a multispecies case study of marine connectivity across the Hawaiian archipelago. J Mar Biol. 2011; https://doi.org/10.1155/2011/460173.

23. von der Heyden $\mathrm{S}$, Beger M, Toonen RJ, van Herwerden L, Juinio-Meñez MA, Ravago-Gotanco R, et al. The application of genetics to marine management and conservation: examples from the indo-Pacific. Bull Mar Sci. 2014;90:123-58.

24. Conte GL, Arnegard ME, Peichel CL, Schluter D. The probability of genetic parallelism and convergence in natural populations. Proc R Soc Lond B Biol Sci. 2012;279:5039-47.

25. Westram AM, Galindo J, Alm Rosenblad M, Grahame JW, Panova M, Butlin RK. Do the same genes underlie parallel phenotypic divergence in different Littorina saxatilis populations? Mol Ecol. 2014;23:4603-16.

26. Grémillet D, Lewis S, Drapeau L, van Der Lingen CD, Huggett JA, Coetzee $J C$, et al. Spatial match-mismatch in the Benguela upwelling zone: should we expect chlorophyll and sea-surface temperature to predict marine predator distributions? J Appl Ecol. 2008;45:610-21.

27. Sink K, Holness S, Harris L, Majiedt P, Atkinson L, Robinson T, et al. National Biodiversity Assessment 2011: technical report. Volume 4: Marine and Coastal Component. Pretoria: South African National Biodiversity Institute; 2012.

28. Majiedt P, Holnes S, Sink K, Oosthuizen A, Chadwick P. Systematic Marine Biodiversity Plan for the West Coast of South Africa. Unpublished report. Cape Town: South Africa National Biodiversity Institute; 2013. p. 46.

29. Bustamante RH, Branch GM, Eekhout S, Robertson B, Zoutendyk P, Schleyer M, et al. Gradients of intertidal primary productivity around the coast of South Africa and their relationships with consumer biomass. Oecologia. 1995;102:189-201.

30. Andrews W, Hutchings L. Upwelling in the southern Benguela current. Prog Oceanogr. 1980;9:1-81.

31. Hutchings L, Van der Lingen CD, Shannon LJ, Crawford RJ, Verheye HM, Bartholomae $\mathrm{CH}$, et al. The Benguela current: an ecosystem of four components. Prog Oceanogr. 2009;83:15-32.

32. Henriques R, McKeown NJ, Shaw PW. Isolation of 12 microsatellite markers for geelbeck (Atractoscion aequidens (Cuvier, 1860), Sciaenidae), an overexploited marine fish. Conserv Genet Resour. 2012;4:85-7.

33. Henriques R, Potts WM, Santos CV, Sauer WH, Shaw PW. Population connectivity and phylogeography of a coastal fish, Atractoscion aequidens (Sciaenidae), across the Benguela current region: evidence of an ancient vicariant event. PLoS One. 2014;9:e87907.

34. Muller CM, von der Heyden S, Bowie RCK, Matthee CA. Linking oceanic circulation, local upwelling and palaeoclimatic changes to the phylogeography of larval dispersal in the southern African Cape Sea urchin, Parechinus angulosus. Mar Ecol Prog Ser. 2012;468:203-15.

35. Wright D, Bishop JM, Matthee CA, von der Heyden S. Genetic isolation by distance reveals restricted dispersal across a range of life-histories: implications for biodiversity conservation planning across highly variable marine environments. Divers Distributions. 2015;21:698-710.

36. Jansen T, Kristensen K, Kainge P, Durholtz D, Strømme T, Thygesen UH, et al. Migration, distribution and population (stock) structure of shallow-water hake (Merluccius capensis) in the Benguela current large marine ecosystem inferred using a geostatistical population model. Fish Res. 2016;179:156-67.

37. Mertens LEA. Using gene flow and phylogeography of multiple marine species to plan a marine protected area network for the west coast of South Africa. South Africa: MS thesis. Stellenbosch University; 2012.

38. Selkoe KA, Watson JR, White C, Horin TB, lacchei M, Mitarai S, et al. Taking the chaos out of genetic patchiness: seascape genetics reveals ecological and oceanographic drivers of genetic patterns in three temperate reef species. Mol Ecol. 2010;19:3708-26. 
39. Selkoe KA, Aloia CCD, Crandall ED, lacchei M, Liggins L, Puritz JB, et al. A decade of seascape genetics: contributions to basic and applied marine connectivity. Mar Ecol Prog Ser. 2016;554:1-19.

40. Gleason LU, Burton RS. Genomic evidence for ecological divergence against a background of population homogeneity in the marine snail Chlorostoma funebralis. Mol Ecol. 2016;25:3557-73.

41. Branch G, Griffiths CL, Branch ML. Beckley LE two oceans: a guide to the marine life of southern Africa. 6th ed. Cape Town: New Holland Publishers; 2007.

42. Nielsen ES, Beger M, Henriques R, Selkoe KA, von der Heyden S. Multispecies genetic objectives in spatial conservation planning. Conserv Biol. 2017;31:872-82.

43. Ekblom R, Galindo J. Applications of next generation sequencing in molecular ecology of non-model organisms. Heredity. 2011;107:1-15.

44. Feldmeyer B, Wheat CW, Krezdorn N, Rotter B, Pfenninger M. Short read Illumina data for the de novo assembly of a non-model snail species transcriptome (Radix balthica, Basommatophora, Pulmonata), and a comparison of assembler performance. BMC Genomics. 2011:12:317.

45. Ellegren $\mathrm{H}$. Genome sequencing and population genomics in non-model organisms. Trends Ecol Evol. 2014;29:51-63.

46. Toonen RJ, Puritz JB, Forsman ZH, Whitney $\mathrm{J}$, Fernandez-Silva I, Andrews $\mathrm{KR}$, et al. ezRAD: a simplified method for genomic genotyping in nonmodel organisms. PeerJ. 2013;1:e203.

47. Kofler R, Orozco-terWengel P, De Maio N, Pandey RV, Nolte V, Futschik A, et al. PoPoolation: a toolbox for population genetic analysis of next generation sequencing data from pooled individuals. PLoS One. 2011;6:e15925.

48. Kofler R, Pandey RV, Schlötterer C. PoPoolation2: identifying differentiation between populations using sequencing of pooled DNA samples (pool-Seq). Bioinformatics. 2011;27:3435-6.

49. Luu K, Bazin E, Blum MG. Pcadapt: an R package to perform genome scans for selection based on principal component analysis. Mol. Ecol Res. 2017:17:67-77.

50. Emanuel BP, Bustamante RH, Branch GM, Eekhout S, Odendaal FJ. A zoogeography and functional approach to the selection of marine reserves on the west coast of South Africa. Afr J Mar Sci. 1992;12:341-54

51. Beger M, Selkoe KA, Treml E, Barber PH, von der Heyden S, Crandall ED, et al. Evolving coral reef conservation with genetic information. Bull Mar Sci. 2014:90:159-85.

52. von der Heyden S. Making evolutionary history count: biodiversity planning for coral reef fishes and the conservation of evolutionary processes. Coral Reefs. 2017;36:183-94

53. Zarraonaindia I, Iriondo M, Albaina A, Pardo MA, Manzano C, Grant WS, et al. Multiple SNP markers reveal fine-scale population and deep phylogeographic structure in European anchovy (Engraulis encrasicolus L.). PLoS One. 2012;7:e42201.

54. Bélanger-Deschênes $S$, Couture P, Campbell PG, Bernatchez L. Evolutionary change driven by metal exposure as revealed by coding SNP genome scan in wild yellow perch (Perca flavescens). Ecotoxicology. 2013;22:938-57.

55. Xu S, Song N, Zhao L, Cai S, Han Z, Gao T. Genomic evidence for local adaptation in the ovoviviparous marine fish Sebastiscus marmoratus with a background of population homogeneity. Sci Rep. 2017;7:2045-322.

56. KaweckiTJ,EbertD.Conceptualissuesinlocaladaptation.EcolLett.2004;7 1225-41.

57. Sanford E, Kelly MW. Local adaptation in marine invertebrates. Annu Rev Mar Sci. 2011;3:509-35.

58. Gienapp P, Teplitsky C, Alho JS, Mills JA, Merilä J. Climate change and evolution: disentangling environmental and genetic responses. Mol Ecol. 2008:17:167-78.

59. Reusch TB. Climate change in the oceans: evolutionary versus phenotypically plastic responses of marine animals and plants. Evol Appl. 2014;7:104-22

60. Morin PA, Luikart G, Wayne RK. SNPs in ecology, evolution and conservation. Trends Ecol Evol. 2004;19:208-16.

61. Cameron RA, Chow SH, Berney K, Chiu TY, Yuan QA, Krämer A. An evolutionary constraint: strongly disfavored class of change in DNA sequence during divergence of cis-regulatory modules. PNAS. 2005;102:11769-74.

62. Britten RJ, Rowen L, Williams J, Cameron RA. Majority of divergence between closely related DNA samples is due to indels. PNAS. 2003;100:4661-5.

63. Balhoff JP, Wray GA. Evolutionary analysis of the well characterized endo16 promoter reveals substantial variation within functional sites. PNAS. 2005; 102:8591-6.

64. Shafer A, Peart CR, Tusso S, Maayan I, Brelsford A, Wheat CW, et al. Bioinformatic processing of RAD-seq data dramatically impacts downstream population genetic inference. Methods Ecol Evol. 2017;8:907-17.
65. Lachance J, Tishkoff SA. SNP ascertainment bias in population genetic analyses: why it is important, and how to correct it. BioEssays. 2013:35:780-6.

66. Reitzel AM, Herrera S, Layden MJ, Martindale MQ, Shank TM. Going where traditional markers have not gone before: utility of and promise for RAD sequencing in marine invertebrate phylogeography and population genomics. Mol Ecol. 2013:22:2953-70.

67. Sodergren E, Weinstock GM, Davidson EH, Cameron RA, Gibbs RA, Angerer $\mathrm{RC}$, et al. The genome of the sea urchin Strongylocentrotus purpuratus. Science. 2006:314:941-52.

68. Simakov O, Marletaz F, Cho SJ, Edsinger-Gonzales E, Havlak P, Hellsten U, et al. Insights into bilaterian evolution from three spiralian genomes. Nature. 2013:493:526

69. Elgar G. The evolution of the genome. London: Academic Press; 2005. p. 768

70. Herrera S, Reyes-Herrera PH, Shank TM. Predicting RAD-seq marker numbers across the eukaryotic tree of life. Genome Biol Evol. 2015:7:3207-25.

71. Bansal V, Harismendy O, Tewhey R, Murray SS, Schork NJ, Topol EJ, Frazer KA. Accurate detection and genotyping of SNPs utilizing population sequencing data. Gen Res. 2010;20:537-45.

72. Rellstab C, Zoller S, Tedder A, Gugerli F, Fischer MC. Validation of SNP allele frequencies determined by pooled next-generation sequencing in natural populations of a non-model plant species. PLoS One. 2013;8:e80422.

73. Konczal M, Koteja P, Stuglik MT, Radwan J, Babik W. Accuracy of allele frequency estimation using pooled RNA-Seq. Mol Ecol Res. 2014;14:381-92.

74. Anderson EC, Skaug HJ, Barshis DJ. Next-generation sequencing for molecular ecology: a caveat regarding pooled samples. Mol Ecol. 2014;23:502-12.

75. Kofler R, Langmüller AM, Nouhaud P, Otte KA, Schlötterer C. Suitability of different mapping algorithms for genome-wide polymorphism scans with pool-seq data. G3 (Bethesda). 2016;6:3507-15

76. Therkildsen NO, Palumbi SR. Practical low-coverage genome-wide sequencing of hundreds of individually barcoded samples for population and evolutionary genomics in nonmodel species. Molecular Ecol Resour. 2017:17:194-208.

77. Hutchison DW, Templeton AR. Correlation of pairwise genetic and geographic distance measures: inferring the relative influences of gene flow and drift on the distribution of genetic variability. Evolution. 1999;53:1898-914.

78. Lacy RC. Loss of genetic diversity from managed populations: interacting effects of drift, mutation, immigration, selection, and population subdivision. Conserv Biol. 1987:1:143-58.

79. von der Heyden S, Lipinski MR, Matthee CA. Mitochondrial DNA analyses of the cape hakes reveal an expanding, panmictic population for Merluccius capensis and population structuring for mature fish in Merluccius paradoxus. Mol Phylogenet Evol. 2007;42:517-27.

80. Teske PR, von der Heyden S, McQuaid CD, Barker NP. A review of marine phylogeography in southern Africa. S Afr J Sci. 2011;107:1-11.

81. Fernández R, Schubert M, Vargas-Velázquez AM, Brownlow A, Víkingsson GA, Siebert $U$, et al. A genomewide catalogue of single nucleotide polymorphisms in white-beaked and Atlantic white-sided dolphins. Molecular Ecol Resour. 2016;16:266-76.

82. Dierickx EG, Shultz AJ, Sato F, Hiraoka T, Edwards SV. Morphological and genomic comparisons of Hawaiian and Japanese black-footed albatrosses (Phoebastria nigripes) using double digest RADseq: implications for conservation. Evol Appl. 2015;8:662-78.

83. Freamo H, O'reilly PA, Berg PR, Lien S, Boulding EG. Outlier SNPs show more genetic structure between two bay of Fundy metapopulations of Atlantic salmon than do neutral SNPs. Mol Ecol Resour. 2011:11:254-67.

84. Meirmans PG. Seven common mistakes in population genetics and how to avoid them. Mol Ecol. 2015:24:3223-31.

85. Pérez-Figueroa A, García-Pereira MJ, Saura M, Rolán-Alvarez E, Caballero A. Comparing three different methods to detect selective loci using dominant markers. J Evol Biol. 2010;23:2267-76.

86. Le Corre $\mathrm{V}$, Kremer A. The genetic differentiation at quantitative trait loci under local adaptation. Mol Ecol. 2012:21:1548-66.

87. Harrison S, Hastings A. Genetic and evolutionary consequences of metapopulation structure. Trends Ecol Evol. 1996:11:180-3.

88. Morjan CL, Rieseberg LH. How species evolve collectively: implications of gene flow and selection for the spread of advantageous alleles. Mol Ecol. 2004;13:1341-56.

89. Henriques R, Nielsen ES, Durholtz D, Japp D, von der Heyden S. Genetic population sub-structuring of kingklip (Genypterus capensis-Ophidiidiae), a commercially exploited demersal fish off South Africa. Fish Res. 2017;187: $86-95$. 
90. Siegel DA, Mitarai S, Costello CJ, Gaines SD, Kendall BE, Warner RR, Winters KB. The stochastic nature of larval connectivity among nearshore marine populations. Proc Natl Acad Sci U S A. 2008;105:8974-9.

91. Vähä JP, Erkinaro J, Niemelä E, Primmer CR. Life-history and habitat features influence the within-river genetic structure of Atlantic salmon. Mol Ecol. 2007;16:2638-54.

92. Teske PR, Papadopoulos I, Zardi Gl, McQuaid CD, Edkins MT, Griffiths CL, Barker NP. Implications of life history for genetic structure and migration rates of southern African coastal invertebrates: planktonic, abbreviated and direct development. Mar Biol. 2007;152:697-711.

93. Weersing K, Toonen RJ. Population genetics, larval dispersal, and connectivity in marine systems. Mar Ecol Prog Ser. 2009;393:1-12.

94. Selkoe KA, Toonen RJ. Marine connectivity: a new look at pelagic larval duration and genetic metrics of dispersal. Mar Ecol Prog Ser. 2011;436:291-305.

95. Barton NH. Genetic hitchhiking. Proc R Soc Lond B Biol Sci. 2000;355:1553-62.

96. Wolffe AP. Transcriptional regulation in the context of chromatin structure. Essays Biochem. 2000;37:45-57.

97. El-Osta ASSAM, Wolffe AP. DNA methylation and histone deacetylation in the control of gene expression: basic biochemistry to human development and disease. Gene Expr. 2001;9:63-75.

98. Galindo J, Grahame JW, Butlin RK. An EST-based genome scan using 454 sequencing in the marine snail Littorina saxatilis. J Evol Biol. 2010;23:2004-16.

99. Johnston EC, Forsman ZH, Flot JF, Schmidt-Roach S, Pinzón JH, Knapp IS, Toonen RJ. A genomic glance through the fog of plasticity and diversification in Pocillopora. Sci Rep. 2017;7:5991.

100. Johnston EC, Forsman ZH, Toonen RJ. A simple molecular technique for distinguishing species reveals frequent misidentification of Hawaiian corals in the genus Pocillopora. PeerJ. In press

101. Davidson EH. Gene activity in early development. 2nd ed. New York: Academic Press; 1976.

102. Materna SC, Berney K, Cameron RA. The S. purpuratus genome: a comparative perspective. Dev Biol. 2006;300:485-95.

103. Zbawicka M, Sańko T, Strand J, Wenne R. New SNP markers reveal largely concordant clinal variation across the hybrid zone between Mytilus spp. in the Baltic Sea. Aquat Biol. 2014;21:25-36.

104. Feschotte C, Jiang N, Wessler SR. Plant transposable elements: where genetics meets genomics. Nat Rev Gen. 2002;3:329-41.

105. Ivanov VA, Melnikov AA, Siunov AV, Fodor II, Ilyin YV. Authentic reverse transcriptase is coded by jockey, a mobile Drosophila element related to mammalian LINEs. EMBO J. 1992;10:2489-95.

106. Dolgin ES, Charlesworth $B$. The effects of recombination rate on the distribution and abundance of transposable elements. Genetics. 2008;178:2169-77.

107. Rizzon C, Marais G, Gouy M, Biemont C. Recombination rate and the distribution of transposable elements in the Drosophila melanogaster genome. Genome Res. 2002;12:400-7.

108. Metivier SL, Kim JH, Addison JA. Genotype by sequencing identifies natural selection as a driver of intraspecific divergence in Atlantic populations of the high dispersal marine invertebrate, Macoma petalum. Ecol Evol. 2017;7:8058-72.

109. Bobola N, Merabet S. Homeodomain proteins in action: similar DNA binding preferences, highly variable connectivity. Curr Opin Genet Dev. 2017:43:1-8.

110. Mesías-Gansbiller C, Sánchez JL, Pazos AJ, Lozano V, Martínez-Escauriaza R Pérez-Parallé ML. Conservation of Gbx genes from EHG homeobox in bivalve molluscs. Mol Phylogenet Evol. 2012;63:213-7.

111. Nielsen MG, Gadagkar SR, Gutzwiller L. Tubulin evolution in insects: gene duplication and subfunctionalization provide specialized isoforms in a functionally constrained gene family. BMC Evol Biol. 2010;10:113.

112. Kang SW, Patnaik BB, Hwang HJ, Park SY, Wang TH, Park EB, Chung JM, Song DK, Patnaik HH, Lee JB, Kim C. De novo transcriptome generation and annotation for two Korean endemic land snails, Aegista chejuensis and Aegista quelpartensis, using Illumina paired-end sequencing technology. Int J Mol Sci. 2016;17:379.

113. Menike U, Lee Y, Oh C, Wickramaarachchi WD, Premachandra HK, Park SC, Lee J, De Zoysa M. Oligo-microarray analysis and identification of stressimmune response genes from manila clam (Ruditapes philippinarum) exposure to heat and cold stresses. Molecular Biol Rep. 2014;41:6457-73.

114. Wu L, Wang L, Wu X. Generation and analysis of cDNA library from lipopolysaccharide-stimulated gastropod abalone (Haliotis diversicolor supertexta) hemocytes. Afr J Biotechnol. 2011;10:7975-80.

115. Wang W, Wu Y, Lei $Q$, Liang H, Deng Y. Deep transcriptome profiling sheds light on key players in nucleus implantation induced immune response in the pearl oyster Pinctada martensii. Fish Shellfish Immun. 2017;69:67-77.
116. Ma D, Yang H, Sun L, Chen M. Transcription profiling using RNA-Seq demonstrates expression differences in the body walls of juvenile albino and normal sea cucumbers Apostichopus japonicus. Chin J Oceanol Limnol. 2014;32:34.

117. Kolle G, Georgas K, Holmes GP, Little MH, Yamada T. CRIM1, a novel gene encoding a cysteine-rich repeat protein, is developmentally regulated and implicated in vertebrate CNS development and organogenesis. Mech Dev. 2000;90:181-93.

118. Schluter D, Conte GL. Genetics and ecological speciation. Proc Natl Acad Sci U S A. 2009;106:9955-62.

119. Smalberger JM. Aspects of the history of copper mining in Namaqualand: Doctoral dissertation, University of Cape Town; Cape Town. 1969.

120. Davis AK, Hildebrand M, Palenik B. Gene expression induced by copper stress in the diatom Thalassiosira pseudonana. Eukaryot Cell. 2006:5:1157-68.

121. Galletly BC, Blows MW, Marshall DJ. Genetic mechanisms of pollution resistance in a marine invertebrate. Ecol Appl. 2007:17:2290-7.

122. Hook SE, Osborn HL, Golding LA, Spadaro DA, Simpson SL. Dissolved and particulate copper exposure induces differing gene expression profiles and mechanisms of toxicity in the deposit feeding amphipod Melita plumulosa. Environ Sci Technol. 2014:48:3504-12.

123. Branch G, Branch M. The living shores of southern Africa. Cape Town: Struik Publishers; 1986.

124. Dong Y, Somero GN. Temperature adaptation of cytosolic malate dehydrogenases of limpets (genus Lottia): differences in stability and function due to minor changes in sequence correlate with biogeographic and vertical distributions. J Exp Biol. 2009;212:169-77.

125. Dupont S, Dorey N, Stumpp M, Melzner F, Thorndyke M. Long-term and trans-life-cycle effects of exposure to ocean acidification in the green sea urchin Strongylocentrotus droebachiensis. Mar Biol. 2013;160:1835-43.

126. Kelly MW, Padilla-Gamiño JL, Hofmann GE. Natural variation and the capacity to adapt to ocean acidification in the keystone sea urchin Strongylocentrotus purpuratus. Glob Chang Biol. 2013;19:2536-46.

127. Foo SA, Dworjanyn SA, Poore AG, Byrne M. Adaptive capacity of the habitat modifying sea urchin Centrostephanus rodgersii to ocean warming and ocean acidification: performance of early embryos. PLoS One. 2012;7:e42497.

128. Evans TG, Pespeni MH, Hofmann GE, Palumbi SR, Sanford E. Transcriptomic responses to seawater acidification among sea urchin populations inhabiting a natural pH mosaic. Mol Ecol. 2017;26:2257-75.

129. Nielsen EE, Hemmer-Hansen J, Poulsen NA, Loeschcke V, Moen T, Johansen $T$, et al. Genomic signatures of local directional selection in a high gene flow marine organism; the Atlantic cod (Gadus morhua). BMC Evol Biol. 2009;9:276.

130. Pante E, Rohfritsch A, Becquet V, Belkhir K, Bierne N, Garcia P. SNP detection from de novo transcriptome sequencing in the bivalve Macoma balthica: marker development for evolutionary studies. PLoS One. 2012;7:e52302.

131. Wit P, Palumbi SR. Transcriptome-wide polymorphisms of red abalone (Haliotis rufescens) reveal patterns of gene flow and local adaptation. Mol Ecol. 2013:22:2884-97.

132. Pespeni MH, Barney BT, Palumbi SR. Differences in the regulation of growth and biomineralization genes revealed through long-term common-garden acclimation and experimental genomics in the purple sea urchin. Evolution. 2013:67:1901-14.

133. Sokolova IM, Pörtner HO. Metabolic plasticity and critical temperatures for aerobic scope in a eurythermal marine invertebrate (Littorina saxatilis, Gastropoda: Littorinidae) from different latitudes. J Exp Biol. 2003;206:195-207

134. Andrello M, Mouillot D, Somot S, Thuiller W, Manel S. Additive effects of climate change on connectivity between marine protected areas and larval supply to fished areas. Divers Distributions. 2015;21:139-50.

135. Fumagalli M, Vieira FG, Linderoth $T$, Nielsen R. ngsTools: methods for population genetics analyses from next-generation sequencing data. Bioinformatics. 2014;30:1486-7.

136. Michelleti SJ, Narum SR. Utility of pooled sequencing for association mapping in nonmodel organisms. Mol Ecol Resour, in press.

137. Knapp IS, Puritz JB, Bird CE, Whitney JL, Sudek M, Forsman ZH, et al. ezRAD-an accessible next-generation RAD sequencing protocol suitable for non-model organisms v3.2. 2016. io.protocols dx.doi.org/10.17504/protocols.io.e9pbh5n.

138. Elshire RJ, Glaubitz JC, Sun Q, Poland JA, Kawamoto K, Buckler ES, et al. A robust, simple genotyping-by-sequencing (GBS) approach for high diversity species. PLoS One. 2011;6:e19379.

139. Peterson BK, Weber JN, Kay EH, Fisher HS, Hoekstra HE. Double digest RADseq: an inexpensive method for de novo SNP discovery and genotyping in model and non-model species. PLoS One. 2012;7:e37135. 
140. Davey JW, Cezard T, Fuentes-Utrilla P, Eland C, Gharbi K, Blaxter ML. Special features of RAD sequencing data: implications for genotyping. Mol Ecol. 2013;22:3151-64.

141. Wagner CE, Keller I, Wittwer S, Selz OM, Mwaiko S, Greuter L, Sivasundar A, Seehausen O. Genome-wide RAD sequence data provide unprecedented resolution of species boundaries and relationships in the Lake Victoria cichlid adaptive radiation. Mol Ecol. 2013;22:787-98.

142. Andrews KR, Good JM, Miller MR, Luikart G, Hohenlohe PA. Harnessing the power of RADseq for ecological and evolutionary genomics. Nat Rev Genet. 2016;17:81.

143. Futschik $A$, Schlötterer $C$. The next generation of molecular markers from massively parallel sequencing of pooled DNA samples. Genetics. 2010;186: 207-18.

144. Schlötterer C, Tobler R, Kofler R, Nolte V. Sequencing pools of individuals mining genome-wide polymorphism data without big funding. Nature Rev Genet. 2014;15:749-63.

145. Gautier M, Foucaud J, Gharbi K, Cézard T, Galan M, Loiseau A, et al. Estimation of population allele frequencies from next-generation sequencing data: pool-versus individual-based genotyping. Mol Ecol. 2013; 22:3766-79.

146. Sham P, Bader JS, Craig I, O'Donovan M, Owen M. DNA pooling: a tool for large-scale association studies. Nat Rev Genet. 2002;3:862-871.

147. Andrews S. FastQC: a quality control tool for high throughput sequence data. Available online at: http://www.bioinformatics.babraham.ac.uk/ projects/fastqc. 2010.

148. Bankevich A, Nurk S, Antipov D, Gurevich AA, Dvorkin M, Kulikov AS, et al. SPAdes: a new genome assembly algorithm and its applications to singlecell sequencing. J Comput Biol. 2012;19:455-77.

149. Gurevich A, Saveliev V, Vyahhi N, Tesler G. QUAST: quality assessment tool for genome assemblies. Bioinformatics. 2013;29:1072-5.

150. Li H, Durbin R. Fast and accurate short read alignment with burrowswheeler transform. Bioinformatics. 2009;25:1754-60.

151. Li H. A statistical framework for SNP calling, mutation discovery, association mapping and population genetical parameter estimation from sequencing data. Bioinformatics. 2011:27:2987-93.

152. Meirmans P. GenoDive (version 2.0 b23, manual): software for analysis of population genetic data: Universiteit van Amsterdam; 2013

153. Narum SR, Hess JE. Comparison of $F_{S T}$ outlier tests for SNP loci under selection. Mol Ecol Res. 2011:11:184-94.

154. da Fonseca RR, Albrechtsen A, Themudo GE, Ramos-Madrigal J, Sibbesen JA, Maretty $L$, et al. Next-generation biology: sequencing and data analysis approaches for non-model organisms. Mar Genomics. 2016;30:3-13.

155. Lischer HEL, Excoffier L. PGDSpider: an automated data conversion tool for connecting population genetics and genomics programs. Bioinformatics. 2012;28:298-9.

156. Foll M, Gaggiotti O. A genome-scan method to identify selected loci appropriate for both dominant and codominant markers: a Bayesian perspective. Genetics. 2008:180:977-93.

157. Altschul SF, Madden TL, Schäffer AA, Zhang J, Zhang Z, Miller W, et al. Gapped BLAST and PSI-BLAST: a new generation of protein database search programs. Nucleic Acids Res. 1997;25:3389-402.

158. Oksanen J, Blanchet FG, Friendly M, Kindt R, Legendre P, McGlinn D, et al. vegan: Community ecology package. R package version. 2017;2:4-4. https://CRAN.R-project.org/package=vegan

159. Raj A, Stephens M, Pritchard JK. fastSTRUCTURE: Variational inference of population structure in large SNP data sets. Genetics. 2014;197:573-89.

160. Raj A, Stephens M, . Pritchard JK. fastSTRUCTURE: Variational Inference of Population Structure in Large SNP Data Sets. Genetics. 2014;197:573-89.

\section{Ready to submit your research? Choose BMC and benefit from:}

- fast, convenient online submission

- thorough peer review by experienced researchers in your field

- rapid publication on acceptance

- support for research data, including large and complex data types

- gold Open Access which fosters wider collaboration and increased citations

- maximum visibility for your research: over $100 \mathrm{M}$ website views per year

At BMC, research is always in progress.

Learn more biomedcentral.com/submissions 